http://jmscr.igmpublication.org/home/ ISSN (e)-2347-176x ISSN (p) 2455-0450 crossref DOI: https://dx.doi.org/10.18535/jmscr/v8i4.67

\title{
Study of Glycosylated hemoglobin level in non-diabetic patients with acute coronary syndrome
}

\author{
Authors \\ Dr Kunal Ostwal, Dr Govind Shiddapur, Dr Sumit Khupse, Dr Varun Tiwari, \\ Dr Narendran Sairam, Dr Asmita Samal
}

Department of General Medicine Dr. D. Y. Patil Medical College, hospital and research centre, Pimpri, Pune *Corresponding Author

Dr Kunal Ostwal

\begin{abstract}
Background: Diabetes is a major causative risk factor for the development of ACS \& the adverse outcome after ACS. 'Stress hyperglycaemia' has been defined in different ways by various studies. Transient hyperglycaemia has been recognized as a noticeable feature in ACS and is related to stress (Lakhdar et al., 1984). ${ }^{[1]}$ Glycosylated haemoglobin is thus useful to differentiate between stress hyperglycaemia diabetes mellitus. Glycosylated haemoglobin has more sensitivity and specificity for diagnosing diabetes in acute myocardial infarction patients, than admission hyperglycaemia.

Methods: All the patients presenting with Acute coronary syndrome and with no previous history of diabetes admitted in Department of General Medicine during the study period from September 2017 to August 2019 were included in the study.

Results: Among 100 patients, males were predominant (70\%). 38\% patients were in the age group of 51-60 years of age (max). Most common presenting complaint of patients was chest pain (84\%) followed by dyspnoea (17\%), lower limbedema (16\%), and palpitations (9\%). $58 \%$ patients had HbAlc > $7 \%$ which was considered as raised $42 \%$ had HbAlc within normal limits. $58 \%$ patients had previously unrecognized diabetes mellitus that came to light after HbAlc estimation. This would have been otherwise interpreted as stress hyperglycaemia. Thus, HbAlc estimation permits prompt and precise identification of previously undiagnosed diabetes mellitus.

Conclusion: HbAlc estimation is a useful, simple, easy and quick method for early and quick method for accurate measurement and interpretation of hyperglycaemia following acute myocardial infarction

Keywords: Acute coronary syndrome, HbAlc, Non diabetics.
\end{abstract}

\section{Introduction}

Acute coronary syndrome (ACS) is a spectrum of disorder which include and ST elevated myocardial infarction (STEMI) unstable angina (UA), non-ST elevated myocardial infarction (NSTEMI). It is diagnosed and classified on the basis on clinical features, electrocardiogram (ECG) findings \& serum biochemical markers of myocardial necrosis. The term HbA1c stands for glycated haemoglobin. It is formed when haemoglobin, a protein within red blood cells that carries oxygen throughout our body, joins with glucose and becomes 'glycated'. It is established by nonenzymatic glycation pathway through exposure of haemoglobin to glucose. It measures beta-N-1-deoxy fructosyl component of 
haemoglobin. ${ }^{[2]}$ Simultaneous presence of hyperglycaemia in patients coming with ACS (Acute coronary syndrome) increases the chances of mortality \& morbidity, irrespective of prior diabetic status of the patient. ${ }^{[2]}$ Amongst patients who present with ACS who are previously non diabetics, hyperglycaemia might indicate undiagnosed diabetes or carbohydrate intolerance due to stress or a mixture of both. So, Glycosylated haemoglobin is useful for the detection of diabetes mellitus in acute myocardial infarction when hyperglycaemia due to stress is also an existing possibility as HbA1c does not increase with acute rise in blood glucose.

\section{Methodology}

- The study comprised of 100 patients admitted in Department of Medicine.

- They were assessed according to clinical proforma.

- The necessary investigations which included lipid profile X-ray chest, ECG and Echocardiogram was done after emergency treatment was given. At the time of admission $\mathrm{HbA} 1 \mathrm{C}$ was tested and quantified in each patient.

- HbA1c < 7\% was assigned to be normal while $>7 \%$ was assigned as raised. Follow up of all the patients was taken daily to check for development of any complication and they were reassessed at the time of discharge from hospital to grade their recovery.

\section{Inclusion Criteria}

1) Patients with acute coronary syndrome which included ST segment elevation MI (STEMI), Non-ST-segment Elevation MI (NSTEMI) and unstable angina (UA)

2) Patients without prior history of diabetes

\section{Exclusion Criteria}

1. Patients with previous history of Diabetes will not be included in the study

2. Non-Cardiac causes of angina like anemia, thyroid disorders from the study.
3. Factors affecting HbA1c levels like drugs (dapsone, ART), renal failure.

4. Patients having sepsis, haemoglobinopathy \& hyperthyroidism were excluded from the study group.

\section{Procedure}

Approval was obtained from the Institutional Ethical Committee before commencing the study. A voluntary informed and written consent was taken from the participants and only those who gave consent were included in the study. All participants / relatives were explained regarding possible benefits as well as risk of study in detail.

Consent form was available in English, Hindi and Marathi. In case of illiterate participants/relatives, consent was taken in presence of witness. The witness was considered to be anyone not directly attached to the study.

The personal details of participants and information related to study was strictly kept confidential during study period at all levels.

\section{Data Analysis}

After collection of data, the forms of all patients were revised. Incomprehensible data was matched again with respective participant profile. Data was entered in MS Excel sheet for preparation of 'Master Chart'.

\section{Statistical Analysis}

In a normal distributed Quantitative parameter, the mean values were compared between study groups using Independent sample t-test (2 groups) and ANOVA test for more than two groups \& $\mathrm{P}$ value was considered significant when it was less than 0.05. Chi square or Fischer exact test was used for the association between the exposure and outcome variable in case of categorical variables. $P$ value was considered significant when it was less than 0.05. Statistical analysis was done using IBM SPSS version 20.

\section{Results}

$38 \%$ patients were in the age group of 51-60 years of age (max), with $10 \%$ in $41-50,30 \%$ in $61-70$, $22 \%$ in $71-80$ respectively. 
- Mean age in HbA1c raised group was 62.47 .

- Mean age in HbA1c normal group was 63.33

- In the study out of 100 patients 70 were male with male to female ratio of 7:3.

- Males also predominate in the HbA1c raised group.

- Most common presenting complaint of patients was chest pain followed by dyspnea (17\%), lower limb edema (16\%), and palpitations (9\%)

- $16 \%$ of patients had painless MI.

- Random blood sugars of all 100 patients was done on admission out of which 73 percent had raised blood sugars, that is above $140 \mathrm{mg} / \mathrm{dl}$ whereas $27 \%$ had normal values.

- All 100 patients HbA1c was done and 42 $\%$ had values less than $7 \%$ which was considered as normal.

- 31 percent patients had HbA1c in the range of 7 to $8 \%$.

- 18 percent patients had HbA1c in the range of 8 to $10 \%$.

- 9 percent patients had HbA1c above $10 \%$

- The most common encountered complication was left ventricular failure (21\%) followed by cardiogenic shock (9 $\%$ ) followed by arrythmia in $2 \%$ of cases.

Table: Complications in ACS

\begin{tabular}{|l|c|c|}
\hline Complications & Frequency & Percent \\
\hline No & 68 & 68.0 \\
\hline LVF & 21 & 21.0 \\
\hline Arrhythmia & 2 & 2.0 \\
\hline Shock & 9 & 9.0 \\
\hline Total & 100 & 100.0 \\
\hline
\end{tabular}

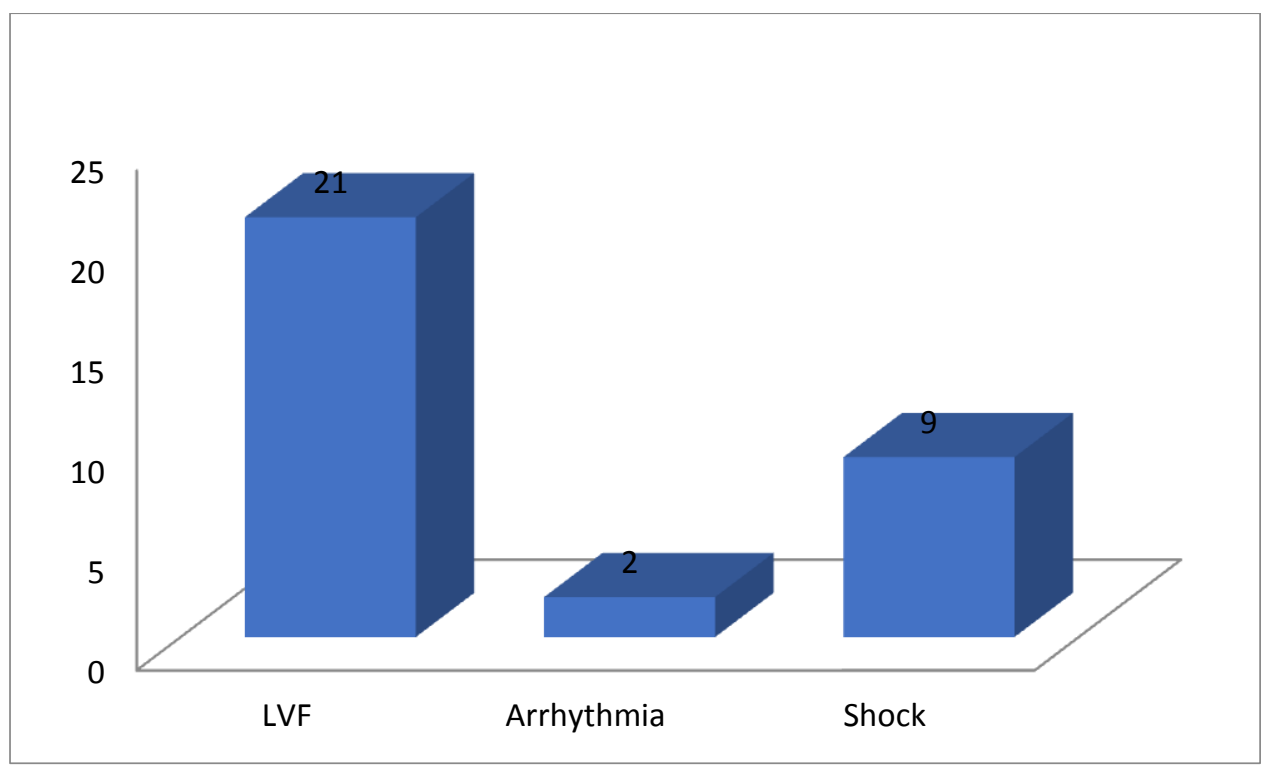

Figure: complications in study subjects

It was also seen that frequency of complications was directly proportional to the level of HbAlc levels

Table: Relationship between $\mathrm{HbA1C}$ and Complications

\begin{tabular}{|c|c|c|c|c|c|}
\hline \multirow{2}{*}{$\begin{array}{l}\text { HbA1C } \\
\text { Level }\end{array}$} & \multicolumn{4}{|c|}{ Complications } & \multirow[b]{2}{*}{ Total } \\
\hline & No & LVF & Arrhythmia & Shock & \\
\hline$<7$ & $33(48.53 \%)$ & $7(33.33 \%)$ & $1(50.00 \%)$ & $1(11.11 \%)$ & 42 \\
\hline $7-8$ & $21(30.88 \%)$ & $8(38.10 \%)$ & 0 & $2(22.22 \%)$ & 31 \\
\hline $8.1-10$ & $11(16.18 \%)$ & $4(19.05 \%)$ & 0 & $3(33.33 \%)$ & 18 \\
\hline$\geq 10.1$ & $3(4.41 \%)$ & $2(9.52 \%)$ & $1(50.00 \%)$ & $3(33.33 \%)$ & 9 \\
\hline TOTAL & 68 & 21 & 2 & 9 & 100 \\
\hline
\end{tabular}




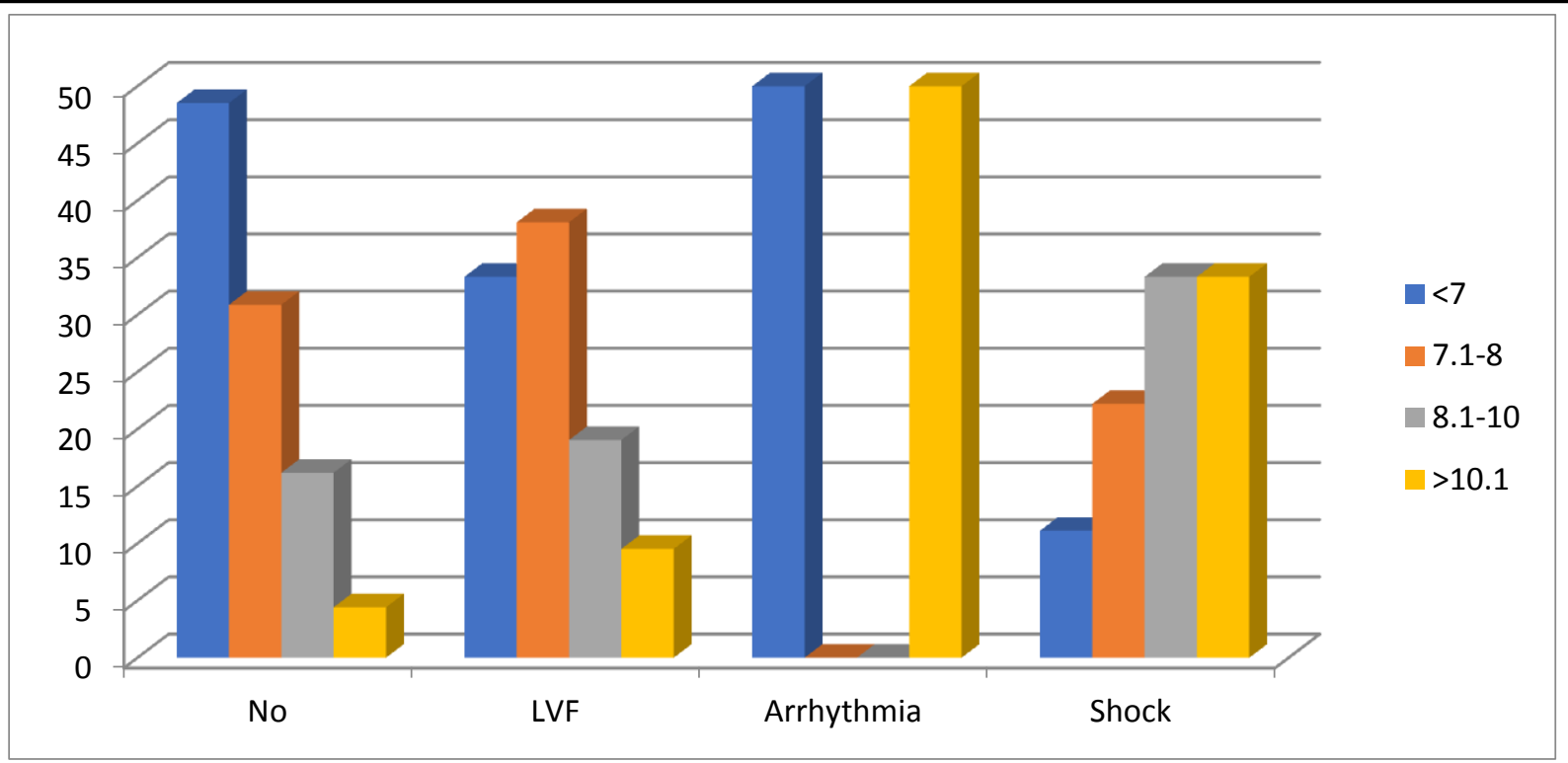

Figure: Relationship between $\mathrm{HbA1C}$ and Complications

Table: HbA1C and Complications

\begin{tabular}{|l|c|c|c|}
\hline \multirow{2}{*}{ HbA1C } & \multicolumn{2}{|c|}{ Complications } & \multirow{2}{*}{ Total } \\
\cline { 2 - 3 } & Absent & Present & \\
\hline$<7$ & $33(78.6 \%)$ & $9(21.4 \%)$ & 42 \\
\hline$>7$ & $35(60.3 \%)$ & $23(39.7 \%)$ & 58 \\
\hline Total & 68 & 32 & 100 \\
\hline
\end{tabular}

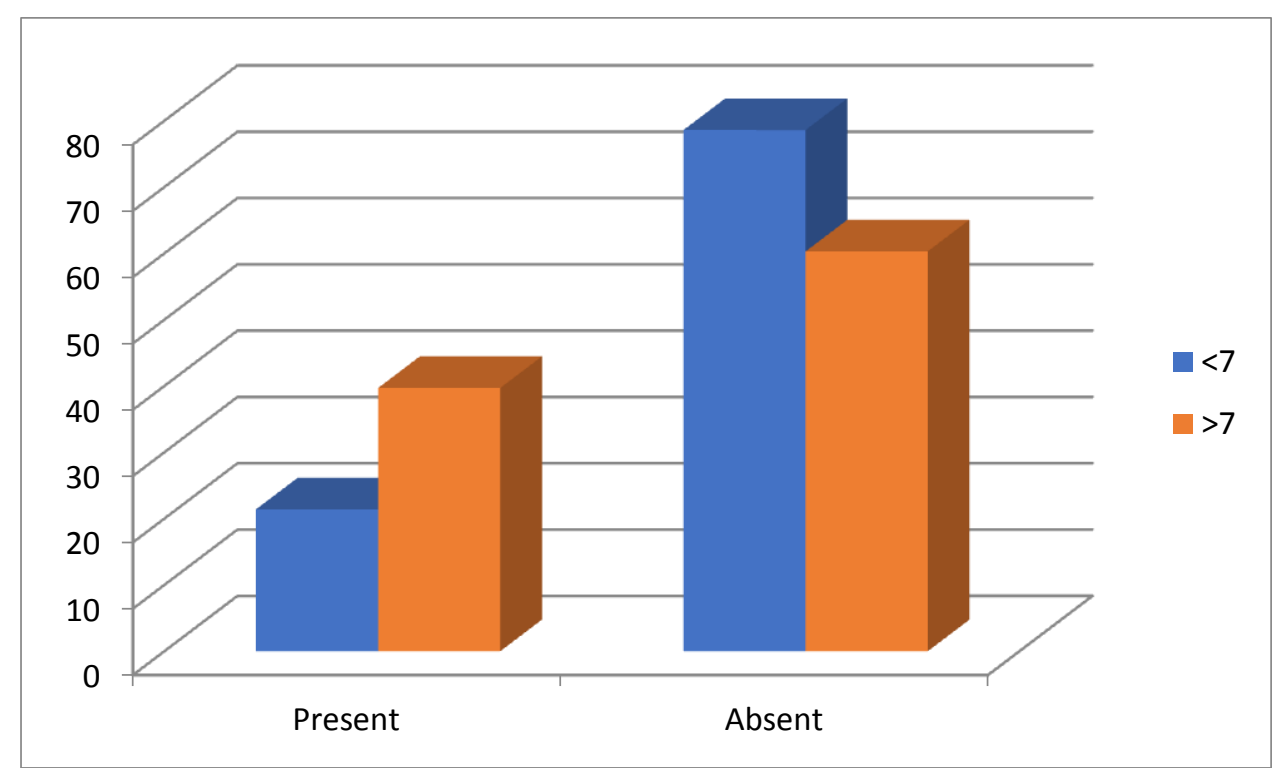

Figure: $\mathrm{HbA1C}$ and Complications

Patients having RBS in excess of 140 at admission also showed a similar correlation and were more prone to undergo complications.

Table: Admission RBS, HbA1C and Complications

\begin{tabular}{|l|c|c|c|c|c|c|}
\hline & ACE & $\mathbf{N}$ & Mean & $\begin{array}{c}\text { Std. } \\
\text { Deviation }\end{array}$ & $\begin{array}{c}\text { Std. Error } \\
\text { Mean }\end{array}$ & P value \\
\hline \multirow{2}{*}{ RBS } & ACE Absent & 68 & 167.29 & 81.091 & 9.834 & 0.003 \\
\cline { 2 - 7 } & ACE Present & 32 & 232.84 & 106.559 & 18.837 & \\
\hline \multirow{2}{*}{ HbA1c } & ACE Absent & 68 & 6.954412 & 1.4406087 & .1746995 & 0.047 \\
\cline { 2 - 7 } & ACE Present & 32 & 7.740625 & 1.9418746 & .3432782 & \\
\hline
\end{tabular}


$86 \%$ of the study subjects recovered well, $11 \%$ had residual dysfunction whereas $3 \%$ patients suffered death in the study.

Table Outcome of ACS

\begin{tabular}{|l|c|c|}
\hline Outcome & Frequency & Percent \\
\hline Recover satisfactory & 86 & 86.0 \\
\hline Residual dysfunction & 11 & 11.0 \\
\hline Death & 3 & 3.0 \\
\hline Total & 100 & 100.0 \\
\hline
\end{tabular}

All 3 deaths were noted in HbA1c higher than 10 group indicating direct relation between level of HbA1c and outcome.

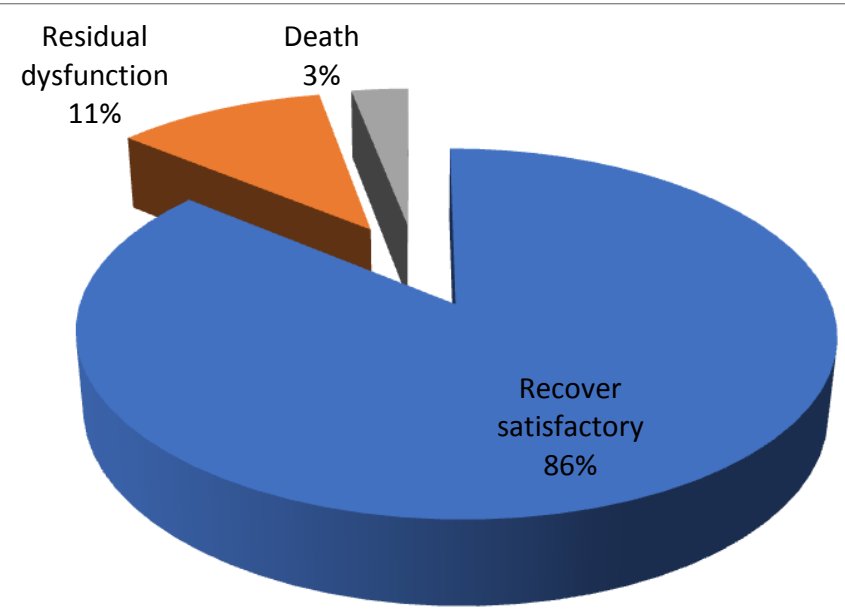

Figure: Outcome of ACS

Table: relationship between $\mathrm{HbA} 1 \mathrm{C}$ and outcome

\begin{tabular}{|l|c|c|c|c|}
\hline \multirow{2}{*}{$\begin{array}{l}\text { HbA1C } \\
\text { Level }\end{array}$} & \multicolumn{3}{|c|}{ OUTCOME } & \multirow{2}{*}{ Total } \\
\cline { 2 - 4 } & $\begin{array}{c}\text { Recovered } \\
\text { satisfactory }\end{array}$ & $\begin{array}{c}\text { Residual } \\
\text { dysfunction }\end{array}$ & Death & \\
\hline$<7$ & $42(48.84 \%)$ & 0 & 0 & 42 \\
\hline $7-8$ & $26(30.58 \%)$ & $5(41.6 \%)$ & 0 & 31 \\
\hline $8.1-10$ & $13(15.29)$ & $5(41.7 \%)$ & 0 & 18 \\
\hline$\geq 10.1$ & $4(4.7)$ & $2(16.7 \%)$ & $3(100 \%)$ & 9 \\
\hline TOTAL & 85 & 12 & 3 & 100 \\
\hline
\end{tabular}

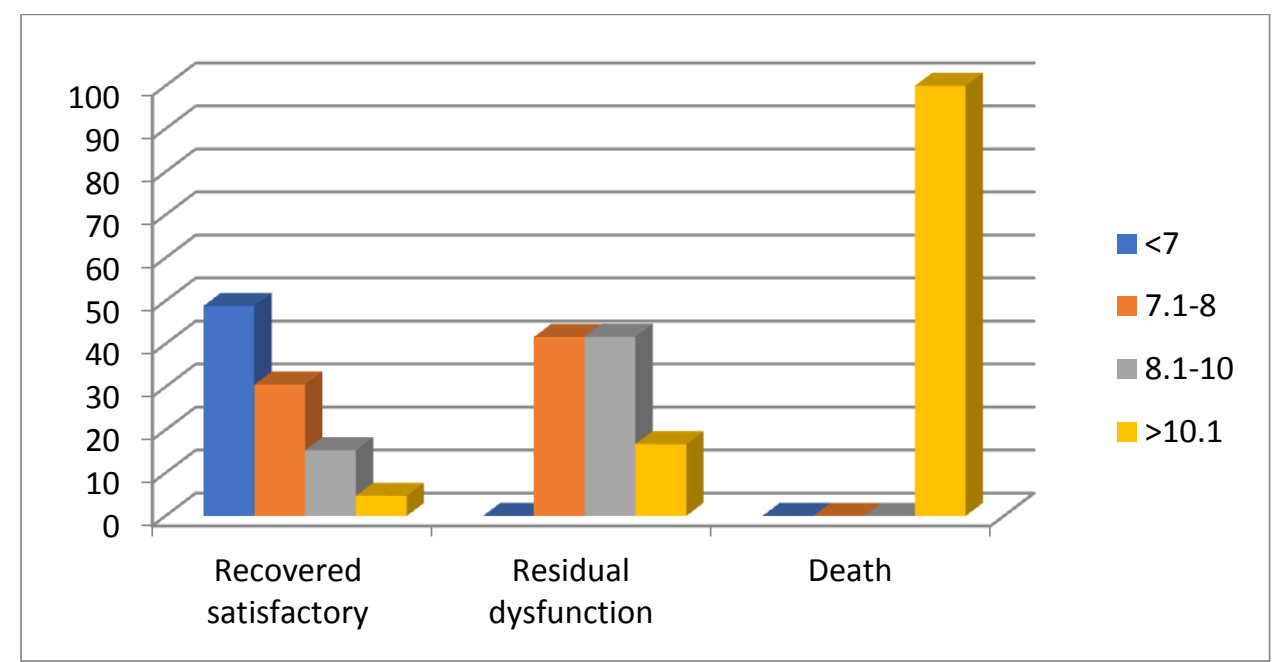

Figure: Relationship between $\mathrm{HbA} 1 \mathrm{C}$ and outcome 
Table: Admission RBS, HbA1C and condition at discharge

\begin{tabular}{|l|c|c|c|c|c|c|}
\hline & N & Mean & $\begin{array}{c}\text { Std. } \\
\text { Deviation }\end{array}$ & $\begin{array}{c}\text { Std. Error } \\
\text { Mean }\end{array}$ & P value \\
\hline \multirow{2}{*}{ RBS } & Recovered & 86 & 172.47 & 83.97 & 9.05 & 0.0001 \\
\cline { 2 - 7 } & Poor outcome & 14 & 285.36 & 101.23 & 27.05 & \\
\hline \multirow{2}{*}{ HbA1c } & Recovered & 86 & 6.922093 & 1.45 & 0.15 & 0.0001 \\
\cline { 2 - 7 } & Poor outcome & 14 & 8.950000 & 1.74 & 0.46 & \\
\hline
\end{tabular}

\section{Discussion}

Glycometabolic state at the time of admission in the hospital is a crucial indicator of risk for mortality in patients suffering with ACS over a long course of time. Increased serum glucose after ACS might occur due either due to stress or may be attributed to unrecognized or undiagnosed diabetes mellitus. It is troublesome to differentiate between the above mentioned two conditions on clinical grounds and estimation of blood glucose levels alone cannot be used as a means for diagnosis for diabetes mellitus. Hence Glycosylated hemoglobin which does not usually rise in acute rise in blood sugar levels could be helpful in detection of diabetes mellitus with coexistence of stress hyperglycemia. In this study 100 patients with ACS were included all of which were non - diabetics. Out of which 73 patients had admission blood glucose level more than 140 $\mathrm{mg} / \mathrm{dl}$. Out of these 73 patients 58 patients had HbA1c levels in excess of $7 \%$. Hence HbA1c is useful in differentiating between stress hyperglycemia and hyperglycemia of diabetes mellitus in AMI.

15 patients who had blood sugar in excess of 140 turned out to have normal $\mathrm{HbAlc}$ values inferring that their hyperglycemia was stress related. Hence dependence on blood sugar estimation alone may be highly unreliable and may prove deleterious if treated.
In the study done by Soler $\mathrm{G}$ et $\mathrm{al}^{[3]}, 31 \%$ patients had blood glucose level more than $140 \mathrm{mg} / \mathrm{dl}$ and of which $13 \%$ patients had HbAlc > $7 \%$.In present study $58 \%$ had HbA1c levels > $7 \%$. Soler $\mathrm{G}$ et al found that $\mathrm{HbA1c}$ testing is of great use for early and accurate detection of increased blood sugars. This estimation allows detection of undiagnosed diabetes mellitus which affects nearly 10 percent of patients who are admitted to the hospital with AMI. ${ }^{[3]}$

In the study by Oswald GA et al admission hyperglycemia was seen in 20 percent of subjects with AMI of which one out of five patients had HbA1c indicating prior diabetes and concluded that $\mathrm{HbA1c}$ is superior and has more sensitivity and specificity for diabetes mellitus in patients with AMI than admission hyperglycemia. ${ }^{[4]}$

In the study by Gokhroo RK et al admission hyperglycemia was found in 25 patients of AMI, of which $8 \%$ had levels of HbA1c indicating diabetes mellitus. Therefore, they concluded that estimation of $\mathrm{HbA} 1 \mathrm{c}$ is a useful parameter. ${ }^{[5]}$

\section{Clinical Profile}

In this study mean age for patients with HbAlc more than 7 was 62.47 whereas of those with HbA1c less than 7 was 63.33 which was found similar to the studies of done by Naseem et $\mathrm{al}^{[6]}$ and Malty AK et $a^{[7] .}$

Table: Studies Comparing Mean Age

\begin{tabular}{|l|c|c|c|}
\hline \multicolumn{1}{|c|}{ Mean age } & Study by Naseem et al & Study by Malty et al & Present study \\
\hline $\begin{array}{l}\text { Mean age in AMI with } \\
\text { raised HbA1c }\end{array}$ & 52.8 & 56.3 & 62.47 \\
\hline $\begin{array}{l}\text { Mean age in AMI with } \\
\text { normal HbA1c }\end{array}$ & 54.6 & 57.8 & 63.33 \\
\hline
\end{tabular}

Diabetic patients were found to be at risk of developing AMI at an earlier age as compared to non-diabetic. 


\section{Symptoms}

$84 \%$ of patients presented with chest pain and all normal HbA1c patients presented with chest pain. So painless myocardial infarction occurred in 16
$\%$ of raised $\mathrm{HbA1c}$ patients which is similar with the study of Bradley et $\mathrm{al}^{[8]}$, Jean et $\mathrm{al}^{[9]}$ and Naseem A et al.

Table: Studies Comparing Painless MI

\begin{tabular}{|l|c|c|c|c|}
\hline Painless MI & Bradley et al & Jean et al & Naseem et al & Present study \\
\hline With Raised HbA1c & $42 \%$ & $24 \%$ & $25 \%$ & $16 \%$ \\
\hline
\end{tabular}

Coronary Angiography was performed in $30 \%$ of patients out of which majority suffered from single vessel disease $(93.3 \%)$ whereas remaining from double vessel disease

The most common encountered vessel in these patients was LAD (60\%) followed by RCA (13.3 $\%)$, LCX (10\%), LMCA (10 \%) and LAD+RCA in $6.7 \%$.

\section{ACS and Clinical Outcome}

Our study showed that $59 \%$ had ST elevation Ml, $41 \%$ non ST elevation M1. While populationbased studies have shown that up to $23.1 \%$ of patients presented with ACS has ST elevation Ml. The common causes of mortality in the diabetics were heart failure, atrial fibrillation, conduction abnormalities and post infarction angina. Diabetic patients show larger infarct size, increased occurrence of left ventricular failure. ${ }^{[10]}$ In our patients acute LVF, arrhythmias, cardiogenic shock were found in $21,2,9 \%$ respectively of which 3 patients died mainly due to Left ventricular failure, ventricular arrhythmias and cardiogenic shock.

In this study, the most common adverse cardiac event observed was left ventricular failure. Several other studies have also made the similar observation. Cardiac failure had been very frequently associated with increased admission plasma sugar value in MI patients. ${ }^{[11]}$

\section{Admission Blood Sugar, HbA1c and Clinical Outcome}

During discharge from hospital 86 had recovered satisfactorily, 11 had complications such as residual ventricular dysfunction, AV block, ventricular septal rupture, mitral regurgitation and 3 patients had died.
In our study the adverse cardiac events such as acute LVF, Ventricular arrhythmias, cardiogenic shock was found in 32 patients following ACS. They had longer duration of stay in hospital, and this was unrelated to the age and sex of the patients. The patients with adverse cardiac events had a mean admission RBS\& HbA1c of 232.84 $\mathrm{mg} \%$ and $7.74 \%$ respectively, while it was 167.29 $\mathrm{mg} / \mathrm{dl}$ and $6.95 \%$ for those without adverse cardiac events.

In this study the mean admission RBS and HbA1c were significantly high in patients with adverse cardiac events. Moreover, patients presenting with above normal admission RBS ( $\geq 140 \mathrm{mg} \%$ ), had more adverse cardiac events. This was statistically significant.

This study had shown that patients with no history of diabetes when presented with an elevated admission RBS have significant adverse cardiac events. Similar observation was made in various other studies. In the study by Mak et al, it has been shown that subjects without DM having elevated admission blood glucose value after the first AMI suffered poor immediate outcome. ${ }^{[12]}$

In our study $\mathrm{HbA1c}$ values also predicted adverse cardiac events in non-diabetic patients. As the values of HbA1c and frequency of occurrence of adverse cardiac events had a direct correlation. Adverse cardiac events were seen only in $21 \%$ of patients in the normal HbA1c group whereas it went up to $39.7 \%$ in patients with raised HbA1c. These findings were found similar to the studies done by Bertoni et $\mathrm{al}^{[13]}$ and $\mathrm{Lu}$ et $\mathrm{al}^{[14]}$. Hyperglycemia results inactivation of apoptosis \& myocyte necrosis, which then leads to systolic and diastolic dysfunction. ${ }^{[15]}$ The UKPDS study indicated that if strict glycemic control is achieved 
with $(\mathrm{HbA} 1 \mathrm{c}<7 \%)$, the risk of myocardial infarction reduces by $16 \%$, but this association was not found to be statistically significant.

Khaw et al found that there is a continuous and significant association between $\mathrm{HbAlc}$, cardiovascular events and mortality. Patients who had HbA1c levels less than 5\%, their rates of cardiovascular disease and mortality is lowest .They also inferred that $1 \%$ increase in the HbA1c is in association with a relative risk of death of 1.24 in men and 1.28 in women ${ }^{[16]}$ Selvin et al in his study concluded that there is no risk of Acute coronary syndrome in patients with HbA1c $<4.6 \%$. However, for every one percent increase inHbA1c over $5.6 \%$, there was 2.5 times increase in risk of cardiovascular disease ${ }^{[17]}$

Individuals with a prolonged history of DM more often have signs of diabetic neuropathy which can cause atypical symptoms during MI. Hence, diagnosis of MI has become a challenge in such subjects and initiation of proper treatment has often prolonged. Studies have shown that in individuals having ACS, DM has been related with greater mortality rates, both within the hospital as well as during long-term follow-up. ${ }^{[18]}$ In fact, this tends to be the pattern in the entire ACS category.

Elevated plasma sugar value in subjects hospitalized for MI seems to be a frequent phenomenon. Studies have pointed out that there is a greater rate of mortality and other complications due to this. ${ }^{[19]}$

Both $\mathrm{HbA1c}$ and admission glucose may have relation with adverse prognosis. However, our results suggest that increased $\mathrm{HbA1c}$ is a more powerful predictor. The clear association between $\mathrm{HbA1C}$ and prognosis establish the same.

\section{Conclusion}

- Estimation of HbA1c is of utility for sooner $\&$ precise estimation of hyperglycemic state after acute myocardial infarction.

- Estimation of HbAlc at the time of admission to CCU helps in differentiating between stress hyperglycemia in acute myocardial infarction and hyperglycemia found in patients with undetected DM with AMI. Hence, HbA1c estimation at admission permits prompt \& precise identification of previously undiagnosed diabetes mellitus.

- Glycosylated hemoglobin is a more sensitive and specific diagnostic test for diabetes mellitus in patients with acute myocardial infarction than admission hyperglycemia where oral glucose tolerance test was impractical and blood glucose unreliable.

- Adverse cardiac event occurred in nearly 32 $\%$ of ACS patients.

- The most common adverse cardiac event was acute left ventricular failure.

- Levels of HbA1c had direct impact on occurrence of adverse cardiac events and outcome of patients with acute myocardial infarction.

- Higher HbA1c level patients were more prone to undergo complications and residual dysfunction.

- Three patients in the study which suffered death, all had HbA1c levels in excess of $10 \%$ establishing the above-mentioned hypothesis.

- HbA1c can hence be used as a prognostic marker as well as a marker for risk of complications.

\section{References}

1. Lakhdar A, Stromberg P, McAlpine SG. Prognostic importance of hyperglycemia induced by stress after acute myocardial infarction. British medical journal (Clinical research ed.). 1984 Jan 28;288(6413):288.

2. Ceriello A. Acute hyperglycemia: a 'new' risk factor during myocardial infarction. European Heart Journal. 2004 Nov 30;26(4):328-31.

3. Soler NG, Frank S. Value of glycosylated hemoglobin measurements after acute myocardial infarction. Jama. 1981 Oct 9;246(15):1690-3.

4. Oswald GA, Yudkin JS. Hyperglycaemia following acute myocardial infarction: the 
contribution of undiagnosed diabetes. Diabetic medicine. 1987 Jan 2;4(1):68-70.

5. Gokhroo RK, Sethi JP, Bharadwaj B, Mitta SR. Glycosylated hemoglobin in acute myocardial infarction. The Journal of the Association of Physicians of India. 1985 $\mathrm{Jul} ; 33(7): 478$.

6. Naseem A, Moin S. Comparison of diabetics and non-diabetics presenting with acute myocardial infarction. JCPSP. Journal of the College of Physicians and Surgeons Pakistan. 2002;12(6):356-60.

7. Maity AK, Sen AK, Chhetri MK. Profile of coronary problems in myocardial infarction in diabetics and non-diabetics. Journal of the Indian Medical Association. 1986 Feb;84(2):37.

8. Bradley RF, Schonfeld A. Diminished pain in diabetic patients with acute myocardial infarction. Geriatrics (Basel, Switzerland). 1962 May; 17:322-6.

9. MADSEN JK, HAUNSØE S, HELQUIST S, HOMMEL E, MALTHE I, PEDERSEN NT, SENGELØV H, RØNNOW- JESSEN DO, TELMER S, PARVING HH. Prevalence of hyperglycaemia and undiagnosed diabetes mellitus in patients with acute myocardial infarction. Acta medica Scandinavica. 1986 Jan 12;220(4):329-32.

10. Lohitashwa SB. Glycosylated Haemoglobin As A Diagnostic Marker Of Diabetes Mellitus In Acute Myocardial Infarction (Doctoral dissertation).

11. Stranders I, Diamant $M$, van Gelder RE, Spruijt HJ, Twisk JW, Heine RJ, Visser FC. Admission blood glucose level as risk indicator of death after myocardial infarction in patients with and without diabetes mellitus. Archives of internal medicine. 2004 May 10;164(9):982-8.

12. Mak KH, Mah PK, Tey BH, Sin FL, Chia G. Fasting blood sugar level: a determinant for in-hospital outcome in patients with first myocardial infarction and without glucose intolerance. Annals of the Academy of Medicine, Singapore. 1993 May;22(3):291-5.

13. Bertoni AG, Hundley WG, Massing MW, Bonds DE, Burke GL, Goff DC. Heart failure prevalence, incidence, and mortality in the elderly with diabetes. Diabetes care. 2004 Mar 1;27(3):699-703.

14. Lu WQ, Resnick HE, Jablonski KA, Jain AK, Jones KL, Robbins DC, Howard BV. Effects of glycaemic control on cardiovascular disease in diabetic American Indians: the Strong Heart Study. Diabetic medicine. 2004 Apr;21(4):311-7.

15. Cai L, Li W, Wang G, Guo L, Jiang Y, Kang YJ. Hyperglycemia-induced apoptosis in mouse myocardium: mitochondrial cytochrome C-mediated caspase-3 activation pathway. Diabetes. 2002 Jun 1;51(6):193848.

16. Khaw KT, Wareham N, Bingham S, Luben R, Welch A, Day N. Association of hemoglobin A1c with cardiovascular disease and mortality in adults: the European prospective investigation into cancer in Norfolk. Annals of internal medicine. 2004 Sep 21;141(6):413-20.

17. Selvin E, Marinopoulos S, Berkenblit G, Rami T, Brancati FL, Powe NR, Golden SH. Meta-analysis: glycosylated hemoglobin and cardiovascular disease in diabetes mellitus. Annals of internal medicine. 2004 Sep 21;141(6):421-31.

18. Sanjuán R, Núñez J, Blasco ML, Miñana G, Martínez-Maicas H, Carbonell N, Palau P, Bodí V, Sanchis J. Prognostic implications of stress hyperglycemia in acute ST elevation myocardial infarction. Prospective observational study. Revista Española de Cardiología (English Edition). 2011 Mar 1;64(3):201-7.

19. Krishna K, Pathan S, Hiremath S. In-hospital outcome of acute myocardial infarction and its correlation with plasma sugar levels. Journal of Indian College of Cardiology. 2012 Jun 1;2(2):59-63. 
Abbreviations

\begin{tabular}{|l|l|l|}
\hline ACS & $:$ & Acute Coronary Syndrome \\
\hline STEMI & $:$ & ST Elevation Myocardial Infarction \\
\hline UA & $:$ & Unstable Angina \\
\hline NSTEMI & $:$ & Non-ST Elevation Myocardial Infarction \\
\hline ECG & $:$ & Electocardiogram \\
\hline CAD & $:$ & Coronary Artery Disease \\
\hline CHD & $:$ & Coronary Heart Disease \\
\hline CRP & $:$ & C Reactive Protein \\
\hline Tpa & $:$ & tissue Plasminogen Activator \\
\hline PAI-I & $:$ & Plasminogen Activator Inhibitor 1 \\
\hline ADA & $:$ & American Diabetes Association \\
\hline DM & $:$ & Diabetes Mellitus \\
\hline HbA1C & $:$ & Glycosylated Haemoglobin \\
\hline CDC & $:$ & Centre For Disease Control And Prevention \\
\hline CVD & $:$ & Coronary Venous Disease \\
\hline DCCT trial & $:$ & Diabetes Control And Complications Trial \\
\hline EDIC trial & $:$ & Epidemiology Of Diabetes Interventions And Complications \\
\hline MI & $:$ & Myocardial Infacrtion \\
\hline ADVANCE trial & $:$ & Action In Diabetes And Vascular Disease Trial \\
\hline ACCORD trial & $:$ & Action To Control Cardiovascular Risk In Diabetes Trial \\
\hline AMI & $:$ & Acute Myocardial Injury \\
\hline HF & $:$ & Heart Failure \\
\hline CK & $:$ & Creatine Kinase \\
\hline LDH & $:$ & Lactate Dehydrogenase \\
\hline DAPT & $:$ & Dual Anti Platelet Therapy \\
\hline PCI & $:$ & Percutaneous Coronary Intervention \\
\hline CABG & $:$ & Coronary Artery Bypass Graft \\
\hline VSD & $:$ & Ventral Septal Defect \\
\hline MR & $:$ & Mitral Regurgitation \\
\hline UKPDS & $:$ & Left Ventricular Failure \\
\hline LVF & $:$ & Congestive Cardiac Failure \\
\hline CCF & Intra-venous \\
\hline IV & Rlood Sugar Level \\
\hline BSL & \\
\hline RBS & & \\
\hline
\end{tabular}

